\title{
Experimental investigation on the surface and subsurface damages characteristics and formation mechanisms in ultra-precision grinding of $\mathrm{SiC}$
}

\author{
Zhipeng $\mathrm{Li}^{1,2} \cdot$ Feihu Zhang ${ }^{1} \cdot$ Yong Zhang $^{1} \cdot$ Xichun Luo $^{2}$
}

Received: 5 December 2016 / Accepted: 6 March 2017 / Published online: 8 April 2017

(C) The Author(s) 2017. This article is published with open access at Springerlink.com

\begin{abstract}
Surface and subsurface damages appear inevitably in the grinding process, which will influence the performance and lifetime of the machined components. In this paper, ultraprecision grinding experiments were performed on reactionbonded silicon carbide (RB-SiC) ceramics to investigate surface and subsurface damages characteristics and formation mechanisms in atomic scale. The surface and subsurface damages were measured by a combination of scanning electron microscopy (SEM), atomic force microscopy (AFM), raman spectroscopy, and transmission electron microscope (TEM) techniques. Ductile-regime removal mode is achieved below critical cutting depth, exhibiting with obvious plow stripes and pile-up. The brittle fracture behavior is noticeably influenced by the microstructures of RB-SiC such as impurities, phase boundary, and grain boundary. It was found that subsurface damages in plastic zone mainly consist of stacking faults (SFs), twins, and limited dislocations. No amorphous structure can be observed in both $6 \mathrm{H}-\mathrm{SiC}$ and $\mathrm{Si}$ particles in RB-SiC ceramics. Additionally, with the aid of high-resolution TEM analysis, SFs and twins were found within the $6 \mathrm{H}-\mathrm{SiC}$ closed packed plane, i.e., (0001). At last, based on the $\mathrm{SiC}$ structure characteristic, the formation mechanisms of SFs and twins were discussed, and a schematic model was proposed to clarify the relationship between plastic deformation-induced defects and brittle fractures.
\end{abstract}

Zhipeng Li

tjb16202@strath.ac.uk; zplihit@gmail.com

1 School of Mechatronics Engineering, Harbin Institute of Technology, Harbin, China

2 Centre for Precision Manufacturing, DMEM, University of Strathclyde, Glasgow, UK
Keywords Ultra-precision grinding $\cdot \mathrm{RB}-\mathrm{SiC}$ ceramics Subsurface damage $\cdot$ Stacking faults $\cdot$ Twins dislocations

\section{Introduction}

In the family of $\mathrm{SiC}, \mathrm{RB}-\mathrm{SiC}$ material has received ever increasing attention as a promising mirror material for space optical applications due to its high strength, high chemical inertness, enhanced radiation stability, thermal shock resistance and high specific stiffness $(E / \rho)[1,2]$. However, due to its extremely high hardness, brittleness, and low fracture toughness, machining RB-SiC becomes a very challenging task. To obtain high form accuracy and surface integrity parts, grinding with diamond wheels is often employed to machine hard and brittle ceramics in various abrasive machining methods [3-5]. But some undesirable surface and subsurface damage such as micro cracks, pulverization layer induced by brittle fracture, and plastic deformation defects are easy to generate in the grinding process, which will impact the surface integrity and reduce the lifetime of the machined components [6]. Conversely, the ductile regime machining method is emerging as a good way to solve the fracture problem, in which work materials are removed in the form of sheared machining chips and leave a crack-free machined surface. Based on the Griffith energy criterion, Bifano et al. [7] proposed that the critical grinding depth for ductile mode grinding of brittle materials was associated with material intrinsic properties. It indicated that the energy required for plastically deformation is less than that for fracture especially at small material removal scale. Also, the damage characters and severity are strongly depend on the material removal mechanism. 
As a consequence, tremendous efforts have been made to investigate material removal mechanism and the corresponding surface and subsurface damages during grinding of difficult-to-machine material such as alumina [8], silicon nitride [9-12], zirconia [13], glasses [14, 15], and particulate reinforced titanium matrix composites $[16,17]$. Specific to silicon carbide ceramics, Agarwal et al. [18] conducted a high machining rate grinding experiments to study the surface/ subsurface damage formation and material removal mechanism. It was found that individual grains dislodgement act as the primary removal mode due to micro cracks propagation along the grain boundaries. The increased depth of cut led to a higher grinding force thus generating larger sized cracks and deeper damage layer. Zhang et al. [19] experimentally distinguished four types of advanced ceramics damage induced in grinding. The results showed that pulverization and scattered cracks are the main grinding damage in the subsurface of $\mathrm{SiC}$, and the damage depth is related to the brittleness property of the work material. Zhang et al. [20] investigated the surface generation mechanism of micro-grinding of $\mathrm{RB}-\mathrm{SiC} / \mathrm{Si}$ composites, and detected that $\mathrm{SiC}$ and $\mathrm{Si}$ phases amorphous transition and $\mathrm{C}$ segregation were occurred in machining by grazing incidence X-ray diffraction and Raman techniques.

Moreover, studies have shown that material removal mechanisms and damage patterns were significantly controlled by the material microstructures. Xu et al. [21] demonstrated that appropriately tailoring $\mathrm{SiC}$ microstructure can result in changing material removal mechanism from macroscopic chipping to grain dislodgment. The tolerance to machining damage can be improved by suppress the formation of strength-degrading cracks. Gao et al. [22] found that the subsurface damage of silicon carbide samples with elongated grain only contain plastic deformation during polishing, while the sample with equiaxed grain appeared lateral cracks both in grinding and polishing.

However, the abrasive-workpiece interaction is very complicated. It is also related to the grit geometry, catastrophic wear of the cutting tool, stress state, machining parameters, intrinsic material properties and crystal anisotropy [23-25]. Therefore, in order to minimize the impact of uncertain factors and monitor what occurred at atomic scale during material removal process in realtime several molecular simulations that only consider the atomic nuclei was performed. Mishra et al. [26] used molecular dynamics simulations (MD) to investigate polycrystalline $\mathrm{SiC}$ wear in the nanoscale range with a nanoscale cutting tool. They attributed atomic scale deformation mechanisms of $\mathrm{SiC}$ to grain-boundary sliding, which is accommodated by heterogeneous nucleation of partial dislocations, formation of voids at the triple junctions due to dislocation restrained and grain pull-out. Whereas, Goel et al. [27] attributed the ductile respond of $\mathrm{SiC}$ to $\mathrm{sp}^{3}-\mathrm{sp}^{2}$ structure transition and amorphization in the nanometric cutting process through MD simulation study. Xiao et al. [28] revealed that intensive dislocation activities, including Frank partial dislocations and basal plane edge dislocations play a major role in the ductile deformation. These MD simulation studies provide a fundamental understanding of material removal and subsurface defects formation mechanisms. However, the simulation conditions are different from real machining process which limits the applicability of the simulation results in real machining practice. Through the research aforementioned, it can be found that the direct observation of the subsurface microstructure in atomic scale under the macroscopic plastic removal mode during ultra-precision grinding of RB-SiC still have not been performed yet.

In this paper, various microcopy techniques will be used to detect surface and subsurface damages of RB-SiC ceramics induced in the ultra-precision grinding experiments. Discussions will be mainly focused on the subsurface damage characteristics and formation mechanisms in the ductile grinding process of $\mathrm{RB}-\mathrm{SiC}$ and the role of grinding depth played in controlling material removal behavior. At last, based on the stress distribution around the abrasives and $\mathrm{RB}-\mathrm{SiC}$ composite microstructures, the correlation of the plastic deformation defects with the crack nucleation and propagation is also analyzed.

\section{Experimental details}

\subsection{Microstructure and material properties of the RB-SiC specimen}

A RB-SiC ceramics cube (dimension, $12.5 \times 12.5 \times 5 \mathrm{~mm}$; Goodfellow Cambridge Ltd., UK) with grain size of about $10 \mu \mathrm{m}$ was used in this study. The specimen was polished until the surface roughness less than $5 \mathrm{~nm} \mathrm{Ra}$ in order to eliminate surface defects. The X-ray diffraction (XRD) pattern (Fig. 1) collected from RB-SiC sample indicates that its composite mainly consists of three phases, i.e., $6 \mathrm{H}-\mathrm{SiC}, 3 \mathrm{C}-\mathrm{SiC}$, and $\mathrm{Si}$. The SEM backscattered electron image of the RB-SiC sample, shown in Fig. 2a, revealed $\mathrm{SiC}$ grains (dark phase) were strongly bonded together into a continuous network and the remaining volume (nearly 10\%) was occupied by silicon (gray phase). While the light parts around $\mathrm{SiC}$ particles are epitaxial overlayers of "new" $\mathrm{SiC}$, which nucleates heterogeneously on the pre-existing $\mathrm{SiC}$ particles during reactionbonding, as marked in SEM secondary electron image Fig. 2b. Some typical material properties of the RB-SiC are listed as follows (obtained from the supplier's official website): elastic modulus $E, 390 \mathrm{GPa}$; Vickers hardness $H$, $3000 \mathrm{kgf} \cdot \mathrm{mm}^{-2}$; compressive strength, $2000 \mathrm{MPa}$; and fracture toughness $K_{I C}, 4.0 \mathrm{MPa} \cdot \mathrm{m}^{1 / 2}$. 


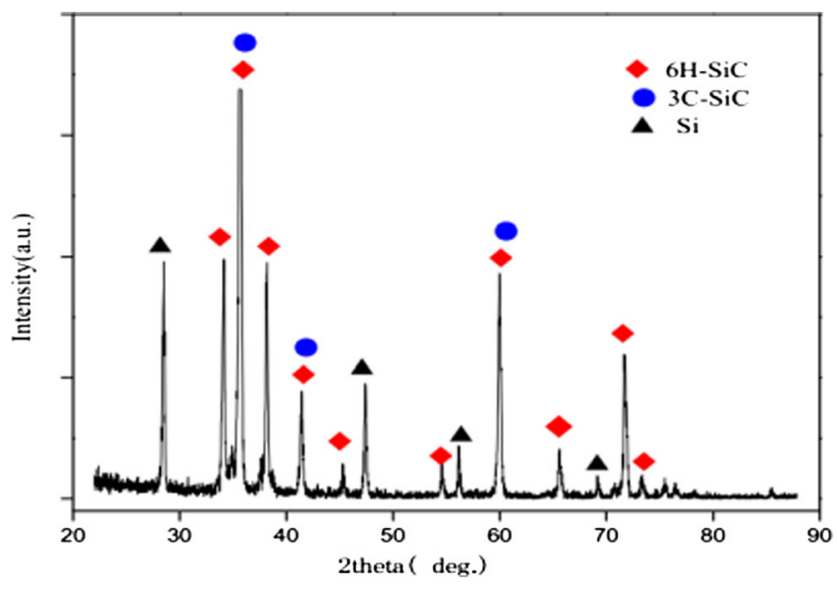

Fig. 1 The XRD pattern collected from RB-SiC

\subsection{Machining conditions and characterization methods}

The grinding experiments were conducted on an ultraprecision machine (Moore Nanotech 350FG). The set-up is shown in Fig. 3. The machining conditions and wheel geometrical parameters are tabulated in Table 1. After completion of the grinding experiments, surface morphology was inspected by a SEM (Dual beam FEI Helios Nanolab 600i) to study the material removal characteristics and the influence of the RB-SiC microstructures. The three-dimensional surface topography of the ground surface was measured by an AFM (Germany Bruker, dimension icon). The Raman spectra of the RB-SiC ceramics was obtained by using a J-Y HR 800 Raman system to identify the change of the subsurface microstructure before and after grinding. An argon ion laser with $488 \mathrm{~nm}$ line excitation wavelength was used in the Raman Microscope. The laser beam was focused to a spot size of $0.8 \mu \mathrm{m}$ in diameter. To minimize experimental error induced by non-uniform distribution of the particles in the matrix of the workpiece, all measurements were performed over five random locations on each machined surface. The cross-sectional lamellae for TEM analysis was prepared by focused ion beam (FIB) in-situ etching (Helios Nanolab600i). The TEM studies were carried out

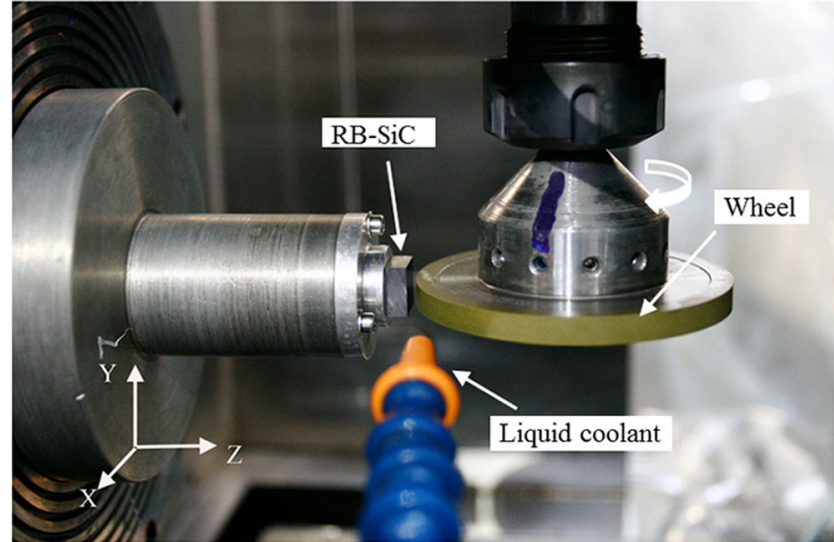

Fig. 3 Experimental set-up of ultra-precision grinding of RB-SiC

using a FEI Talos F200x, operated at $300 \mathrm{kV}$, to observe subsurface defects more intuitively.

\section{Results}

\subsection{Surface morphology observed by SEM}

Figure 4 shows the SEM images of the ground surface under different depth of cut depicted in section 2. In Fig. 4a, b, the plowing stripes and micro-fracture pits appeared on the final machined surface as the depth of cut was set up to 1 and $2 \mu \mathrm{m}$. The irregular fracture pits were mostly nucleated at the sites of SiC: Si phase boundary (P.B.) and SiC: SiC grain boundary (G.B.). They were distributed parallel to the direction of grinding as marked by arrows. This observation is consistent with previous study by Zhang et al. [20]. In the high spindle speed grinding of $\mathrm{RB}-\mathrm{SiC} / \mathrm{Si}$ trial, they found that $\mathrm{P}$. B. always acted as the first site and preference path for crack nucleation and propagation. Such fact is closely associated with the defects evolution mechanism and influenced by the microstructures of RB-SiC (to be discussed in detail later). In addition, Fig. 4b also revealed that some trans-crystalline and inter-granular
Fig. 2 SEM image of the polished RB-SiC. a backscattered electron. b Secondary electron
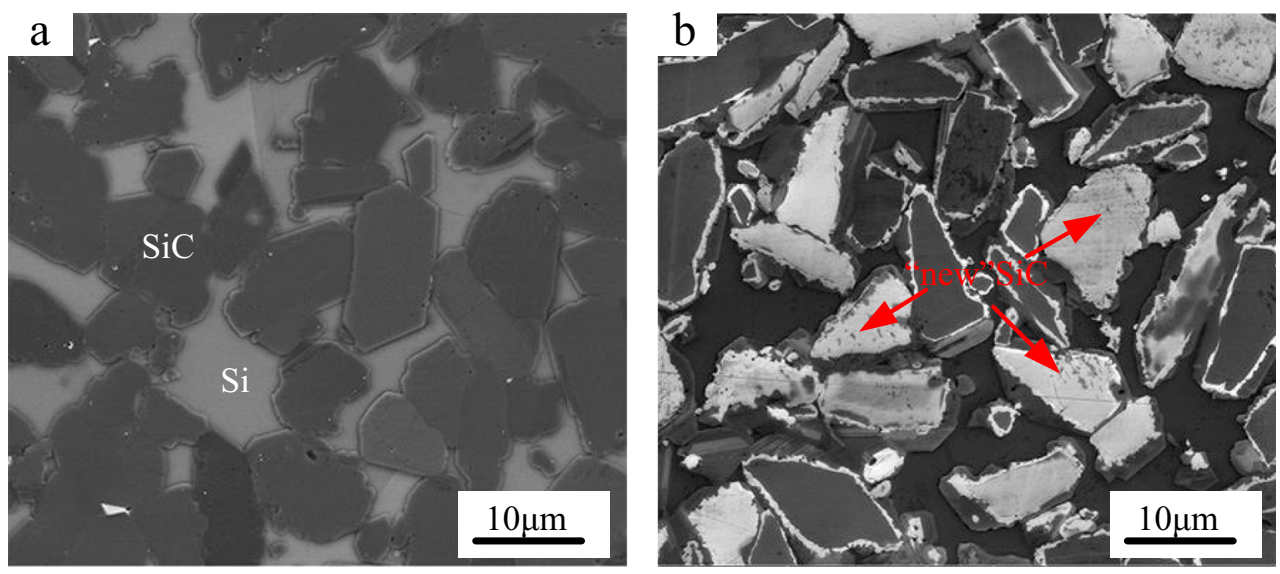
Table 1 Grinding conditions and wheel geometrical parameters

\begin{tabular}{ll}
\hline Diamond wheel & Resin-bonded, $7 \mu \mathrm{m}$ diamond grit, diameter $75 \mathrm{~mm}$, width $6 \mathrm{~mm}$, concentration: $75 \%$. \\
\hline $\begin{array}{l}\text { Truing condition } \\
\text { Coolant }\end{array}$ & Green silicon carbon (GC) rod, \#800, hardness: P \\
& Water-based, challenge $300-\mathrm{HT}$, \\
concentrations: $2-3 \%$, jet speed: $5 \mathrm{~m} / \mathrm{s}$, cross-sectional area of nozzle: $12.56 \mathrm{~mm}^{2}$ \\
Spindle speed & $5000 \mathrm{rpm}$ \\
Feed rate & $2 \mathrm{~mm} / \mathrm{min}$ \\
Depth of cut & $0.1,0.5,1,2 \mu \mathrm{m}$ \\
\hline
\end{tabular}

micro-cracks were lied on the machined surface due to not fully developed. Abovementioned results indicate that the ground surface was generated by the combination of brittle and ductile removal modes.

In contrast to Fig. 4a, b, a high-quality surface barely free from any defects was obtained when the depth of cut was set at 0.1 and $0.5 \mu \mathrm{m}$, as presented in Fig. $4 \mathrm{c}$, d. It was interesting to see that even at the sites of material flaws (such as pores), where always act as sources of stress concentration to amplify the applied stress, any brittle fracture manner was not observed. Instead, the ductile stripes exist in both cases. It can, therefore, confirm that plastically removal mode of RB-SiC can be achieved when conforms to the ductile-regime criteria.

Additionally, plastic deformation characteristics on the ground RB-SiC surface were also evaluated by the AFM as shown in Fig. 5. The plowing stripes akin to metal cutting stripes were clearly seen on the three-dimensional ground surface textures (Fig. 5a). The profiles of a cross-section of the stripes exhibited continuous zigzag pattern, as shown in
Fig. 5b, with the surface roughness about $34.3 \mathrm{~nm}(\mathrm{Ra})$ and $43.5 \mathrm{~nm}(\mathrm{Rq})$. The piled-up materials at the sides of the plowing grooves once again proved that plastic deformation occurred during the grinding process.

\subsection{Raman spectroscopy analysis of RB-SiC}

Raman spectroscopy has been approved to be an effective and simple tool for the characterization of polytypes, disorder, damages, and impurities properties of $\mathrm{SiC}$ [29-31]. The Raman scattering efficiency is relative high for $\mathrm{SiC}$ because of its strong covalent chemical bond. So Raman spectrum can be easily obtained with no destructive, no contact and no special preparation of the samples.

Figure 6 shows the whole Raman spectrum of RB-SiC obtained before grinding in the range of $0-2000 \mathrm{~cm}^{-1}$. The weak bands at the points of 143.5 and $234.2 \mathrm{~cm}^{-1}$ corresponding to the folded modes of transverse acoustic (FTA) of $6 \mathrm{H}-$ $\mathrm{SiC}$ at $\mathrm{q} / \mathrm{q}_{0}=1 / 3$ and $\mathrm{q} / \mathrm{q}_{0}=2 / 3$ ( $\mathrm{q}$ is wave vector),
Fig. 4 SEM micrograph of typical ultra-precision grinding morphology under different depth of cut. $\mathbf{a} \mathrm{a}_{\mathrm{p}}=2 \mu \mathrm{m}$. $\mathbf{b} \mathrm{a}_{\mathrm{p}}=1 \mu \mathrm{m}$. c $\mathrm{a}_{\mathrm{p}}=0.5 \mu \mathrm{m}$. d a $\mathrm{a}_{\mathrm{p}}=0.1 \mu \mathrm{m}$
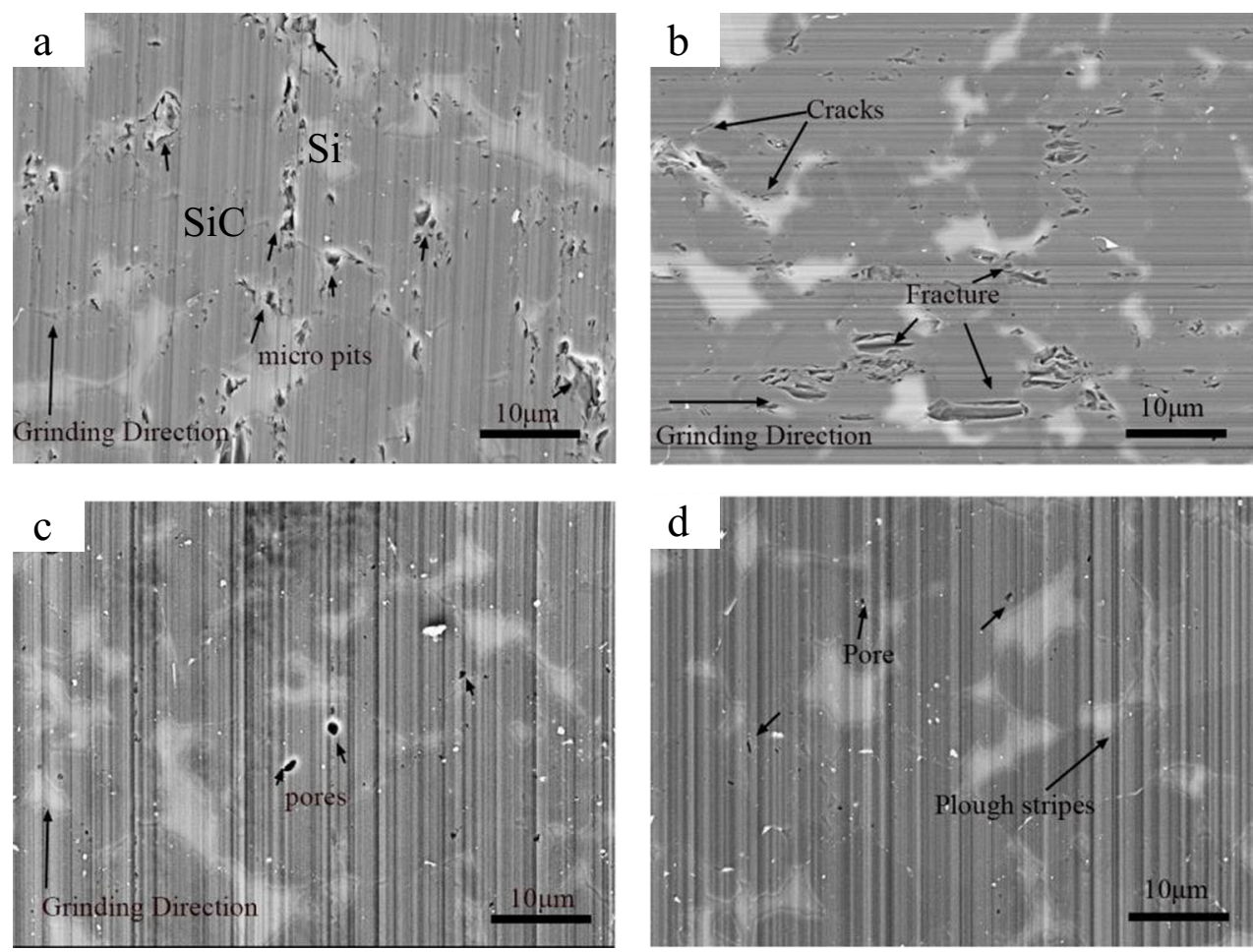


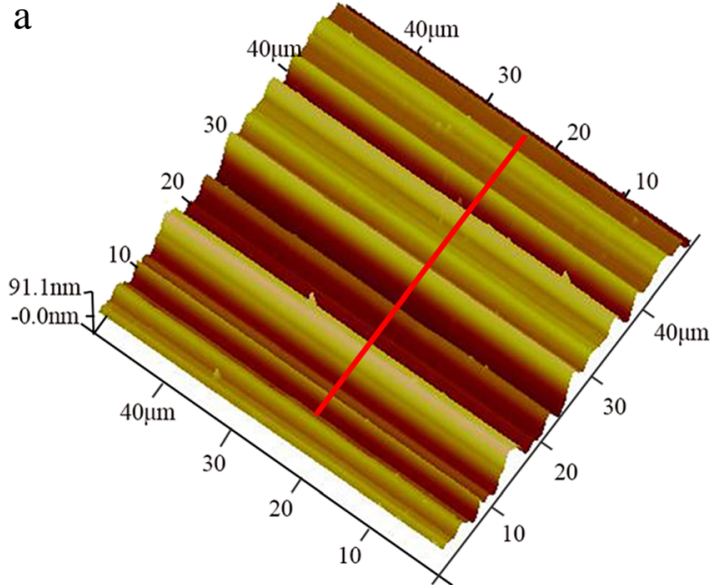

Fig. 5 a AFM image of RB-SiC surface ground under a depth of cut of $0.1 \mu \mathrm{m}$. b the corresponding cross section profile

respectively. According to the literature [31], the folded modes of transverse optic (FTO) of 6H-SiC Raman peaks were at 762.9 and $784.8 \mathrm{~cm}^{-1}$, and longitudinal optic (LO) mode peak was at $964.1 \mathrm{~cm}^{-1}$. While, $\operatorname{FTO}(0)(\mathrm{q}=0)$ at $792.8 \mathrm{~cm}^{-1}$ Raman shift should be ascribed to the stacking faults (SFs), which is associated with both $3 \mathrm{C}-\mathrm{SiC}$ and $4 \mathrm{H}-$ $\mathrm{SiC}$ polytypes.

In the high-frequency region, the Raman shift features at about 1509.9 and $1709.1 \mathrm{~cm}^{-1}$ shift are attributed to the second-order Raman scattering band of $6 \mathrm{H}-\mathrm{SiC}$. Another sharp Raman line observed at the point of $515.9 \mathrm{~cm}^{-1}$ is ascribed to the crystalline $\mathrm{Si}$, arising from the substrate of the bulk crystalline region [32]. We should note that compared with the stress free $6 \mathrm{H}-\mathrm{SiC}$ and $\mathrm{Si}$, both their transverse optic (TO) modes have a lower frequency shifts of $-5 \mathrm{~cm}^{-1}$, indicating tensile residual stress existed in the pristine material.

To discover the change in detail after grinding, Fig. 7a shows the magnification of Raman spectra that belongs to

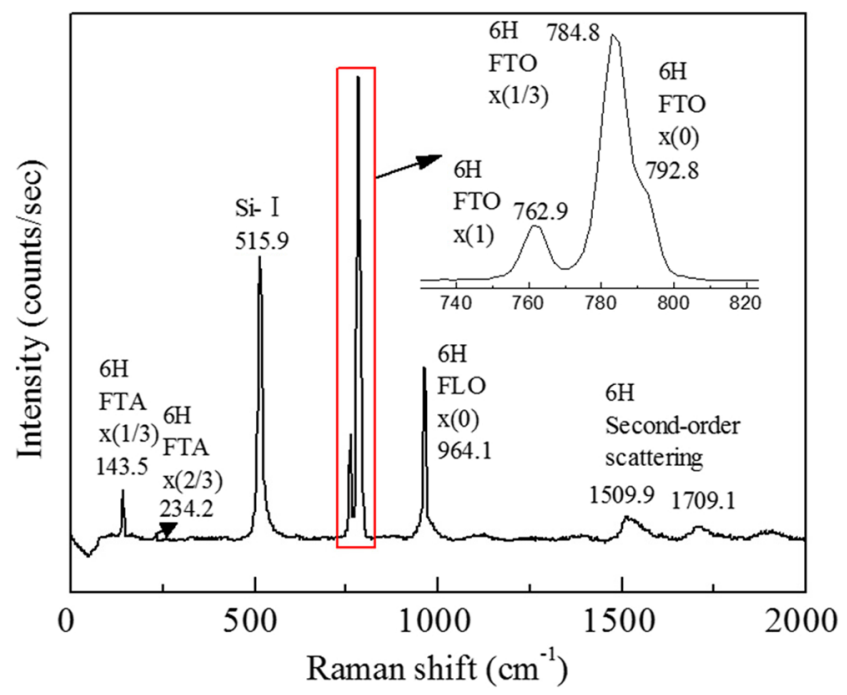

Fig. 6 The whole Raman spectra of RB-SiC before grinding the shift frequency of $\mathrm{Si}$. It can be seen that the $\mathrm{Si}$ bands is separated into two components at about $515 \mathrm{~cm}^{-1}$ and $533 \sim 537 \mathrm{~cm}^{-1}$ with the increasing of grinding depth from 1 to $2 \mu \mathrm{m}$. The same results also occurred at the brittle fracture micro pits (see Fig. 4a), as shown in Fig. 7a the saffron yellow curve, which suggest the deformation degree in silicon is related to the depth of cut. This phenomenon is presumably aroused by the non-uniform distribution of stress which offered by the plastic deformation of dislocations [33, 34]. Under the effect of the anisotropic stress of Si threefold degeneracy phonon modes at Brillouin zone $\mathrm{q}=0$ was broken, resulting in the split of different phonon frequencies.

The main features of partial spectrum of $\mathrm{SiC}$ amplified in the wavenumber range of $700-1100 \mathrm{~cm}^{-1}$ are also shown in Fig. 7b. Compared to the spectrum obtained in pristine RB$\mathrm{SiC}$, there is no significant differences in the positions of the $6 \mathrm{H}-\mathrm{SiC}$ Raman peaks, except for $4 \mathrm{H}-\mathrm{SiC} \mathrm{TO}$ peak located at $770 \mathrm{~cm}^{-1}$ appeared occasionally, which has also found in Ref. [35]. They attribute it to the SFs deformation induced short range ordering $4 \mathrm{H}-\mathrm{SiC}$ like structure with a small volume. Besides, no indication of amorphous phase signal of $\mathrm{SiC}$ was shown up in spectrum. The evidence of the above arguments will be further confirmed by TEM inspection in the next section.

In the high-frequency region, however, the additional broad bands center at 1356 and $1579 \mathrm{~cm}^{-1}$ always appeared in Raman spectrum which was taken from the surface fracture points (shown in Fig. 8). As testified in Ness JN and Page TF [36], the graphite was trapped by the growing grains before its reaction with liquid silicon during $\mathrm{RB}-\mathrm{SiC}$ fabrication. Therefore, those two peaks should be caused by the $\mathrm{D}$ peak (disorder-induced A1g mode) and G peak (E2g mode) of graphite, respectively [37]. Hence, it implied that graphite impurities play an important role on material fracture behavior. They can offer a potential fracture point for crack nucleation. 
Fig. 7 Local amplification Raman spectra of $\mathrm{Si}$ in the range of $450-600 \mathrm{~cm}^{-1}$ (a) and $\mathrm{SiC}$ in the range of $700-1000 \mathrm{~cm}^{-1}$ (b)

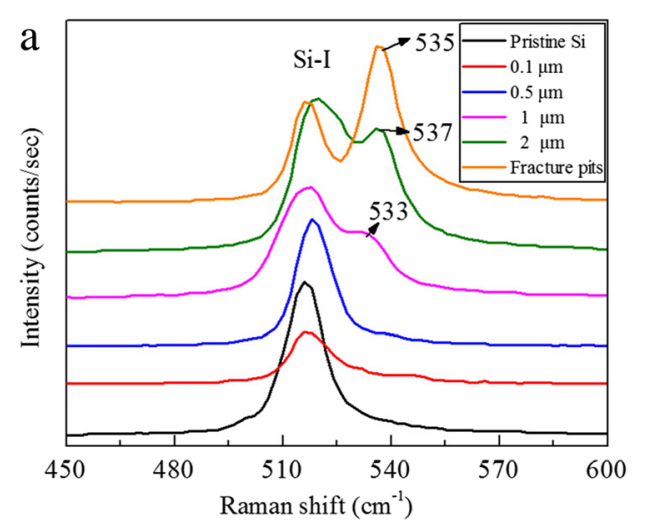

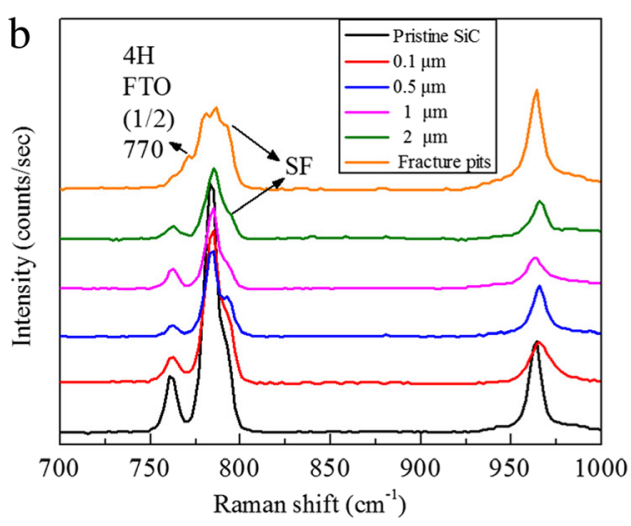

\subsection{Cross-section of the ground $\mathrm{SiC}$ surface observed by TEM}

The SiC sample was prepared from the plastic zone of the ground surface under the depth of cut of $0.1 \mu \mathrm{m}$. Figure 9a shows a TEM image of the cross section with the whole view of subsurface structure that contains three different orientations of $\mathrm{SiC}$ crystals and one $\mathrm{Si}$ grain. The proportion of $\mathrm{Si}$ is too small to play a dominant role in deciding the degree of machined subsurface damage. Hence, the observation was mainly placed on the $6 \mathrm{H}-\mathrm{SiC}$ grain for this part. The TEM image shows that the crystalline defect layer is deeper than the depth of cut. No crack was observed. To future explore the subsurface damage patterns, some magnified images of the locations marked in Fig. 9a are shown in b, d, and e. Fig. 9b is the corresponding magnification bright field image (BF) of area "a," imaged down $<1 \overline{2} 10>$ zone axes, showing a high density of straight and narrow streaks, whose features are consistent with the $\mathrm{SiC}$ stacking faults (SFs) microstructure observed by SONG et al. as highlighted by arrows [38]. Those SFs planar defects are responsible for the appearance of

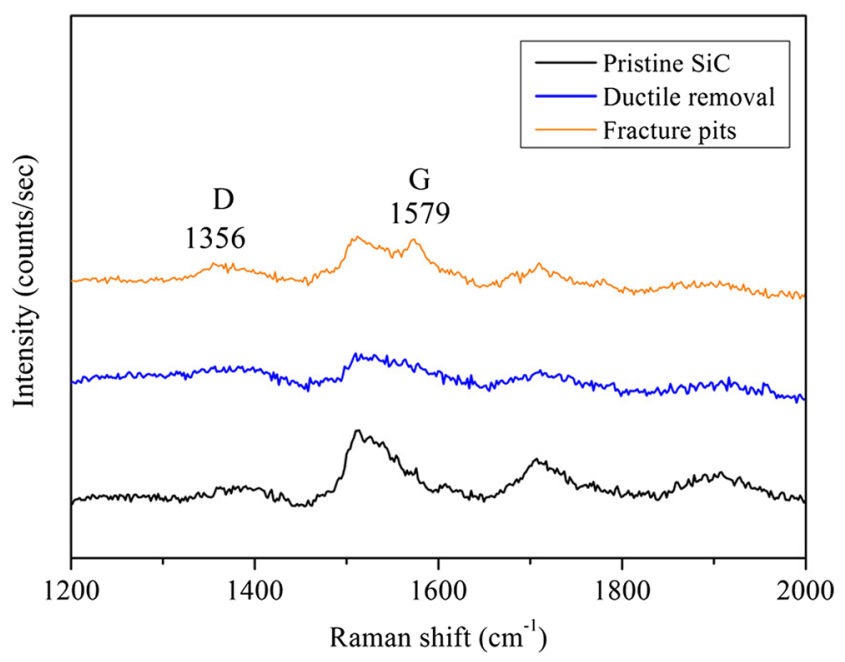

Fig. 8 Raman spectrum of graphite contained in RB-SiC
FTO(0) Raman peak at about $794 \mathrm{~cm}^{-1}$ shift signal before grinding (shown in Fig. 7b). The corresponding selected area diffraction (SAD) pattern, which inserted in Fig. 9b displays a set of brightness spots varies with a period of six if excludes the twins spots. According to the previous study, such characteristics can be used to depict $6 \mathrm{H}-\mathrm{SiC}$ polytype (This $\mathrm{SiC}$ grain structure was further confirmed by titling the sample to take other SAD. For simplicity the result is not shown in this paper). The diffraction spots streaks develop perpendicularly to the fault plane along the (0001) direction, indicating SFs are within the basal plane (0001). Such fault plane is common in $\mathrm{HCP}$ structure and is easy to generate in the sintering process due to its lower stacking faults energy (SFE) [39].

A dark straight line was found to occur parallel to the $<1$ $01 \overline{2}>$ direction, of which projection is at about $80^{\circ}$ from the basal plane (circled by the elliptical dotted line in Fig. 10a). Therefore, the propagation of SFs was blocked and terminated in the $\mathrm{SiC}$ grain. Such defects will hinder the plastic deformation in the following grinding process. For the aim of exploring this defects, a higher-magnification view was taken at another orientation and was shown in Fig. 9c, revealing the dark straight line is a low-angle grain boundary surrounded with a high density of discrete dislocations. Moreover, a Si grain that contains several dislocation lines embedded in this $6 \mathrm{H}-\mathrm{SiC}$ grain are visible, which correspond to the Raman shift peaks at about 515 and $533 \sim 537 \mathrm{~cm}^{-1}$, respectively.

Figure 9d is an enlarged image of region " $b$ " with the sample tilting at another orientation, showing SFs with weak contrast and some edge on dislocations at the ends of fringes (marked by arrows) and no twins microstructure inside the grains. Such faults are similar to the phenomenon obtained in the dynamically ruptured SiC-I fragments in modified split Hopkinson bars test, indicating one of the contributions for this portation of SFs is coming from the plastic deformation of the $\mathrm{SiC}$ workpiece [40]. They are formed by the motion of partial dislocations in the basal planes, leaving behind stacking errors in the perfect $\mathrm{SiC}$ crystals. What is more, from the magnified image of location marked "c" in Fig. 9e, only a few of dislocations can be found in the grains and no stacking fault 
Fig. 9 a TEM image of overall cross-section of the RB-SiC grounded surface, observed at the region of $0.1 \mu \mathrm{m}$ depth of cut. $\mathbf{b}$, d, and e local magnification bright field image corresponding to the location as marked by " $a$," " $b$," and "c" in (a), respectively. c Magnified TEM of area marked by elliptical dotted line in (b) a
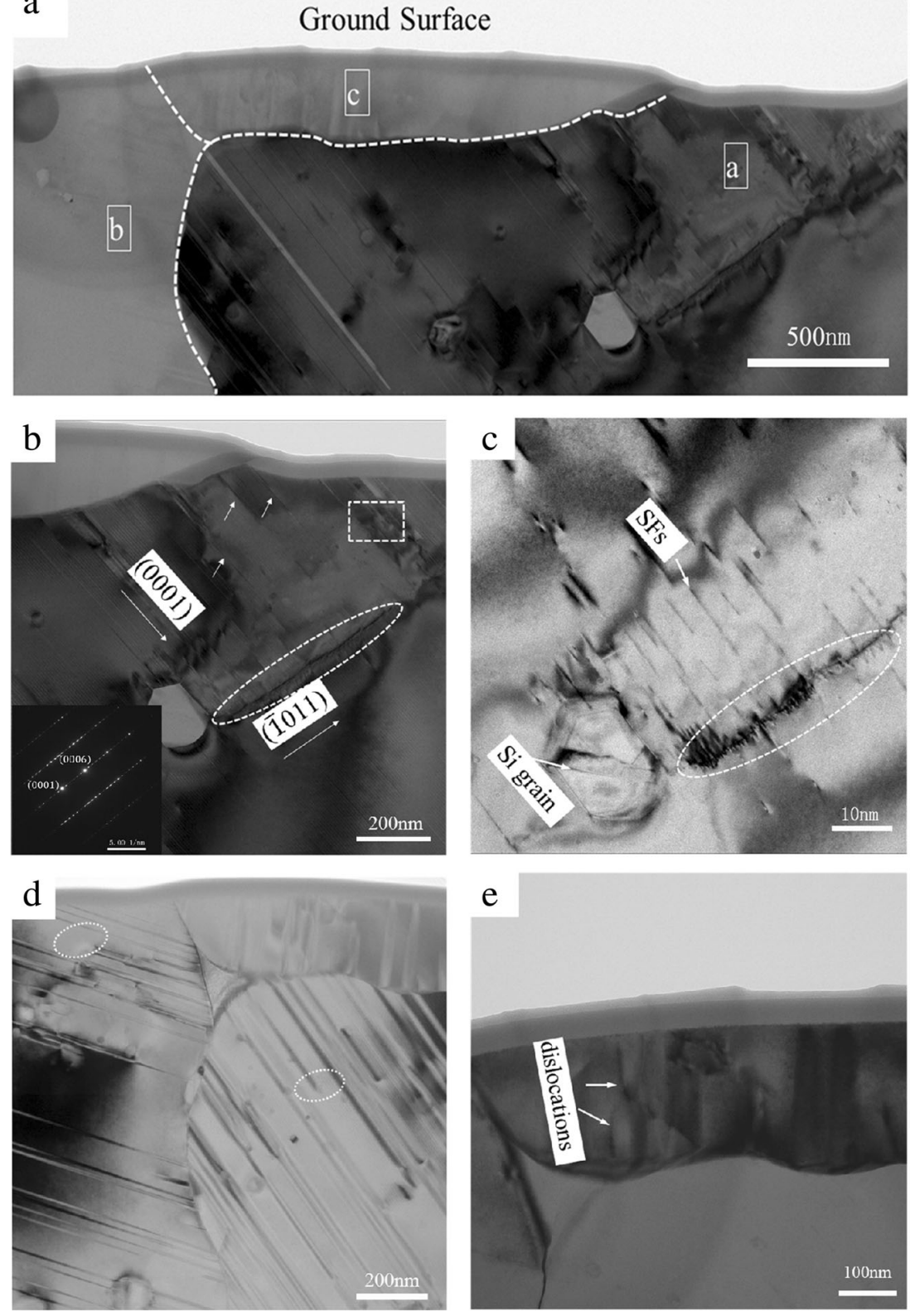

streaks appeared. The limited or absent dislocations motion is due to strong $\mathrm{SiC}$ valence bonds characteristic. All of the above observations suggest that $\mathrm{RB}-\mathrm{SiC}$ subsurface deformation mechanism is more complicated than single crystal $\mathrm{SiC}$ because of its complex microstructure, i.e., differ crystallographic orientation, random distributions and P.B./G.B.

Additionally, even though a pronounced twining patterns can be observed in SAD, it was difficult to distinguish the twins from the extensively SFs streaks in the bright field image. So high resolution TEM (HRTEM) was required to further investigate the details of twins structure. Figure 10a shows a HRTEM image obtained from the region circled in Fig. 9b. Deformation twins exist inside the clustered SFs and parallel to the basal plane. The thickness of the twin is about $3 \mathrm{~nm}$ and we do not find any evidence of amorphous phase occurred in this area. Fig. 10b is the corresponding Fast Fourier transform (FFT) on the area closed by the white box in Fig. 10a, including both matrix and twin part diffraction spots, in which two rhombohedral described the twins relationship. It indicates that the twins plane also lies on the basal plane (0001) as expected in $6 \mathrm{H}-\mathrm{SiC}$.

Moreover, from the corresponding inverse FFT (IFFT) pattern presented in Fig. 10c, the twins boundaries are ledges and irregularities (marked by yellow lines), which is in agreement with the features of deformed boron carbide reinforcement particles (also in covalent bonds) within a nanostructured $\mathrm{Al}$ 
Fig. 10 a The HRTEM image taken from the region enclosed by a rectangle in Fig. 9b. b Corresponding SAD pattern of the image a. c corresponding FFT patterns of HRTEM image in (a). d Inverse FFT pattern
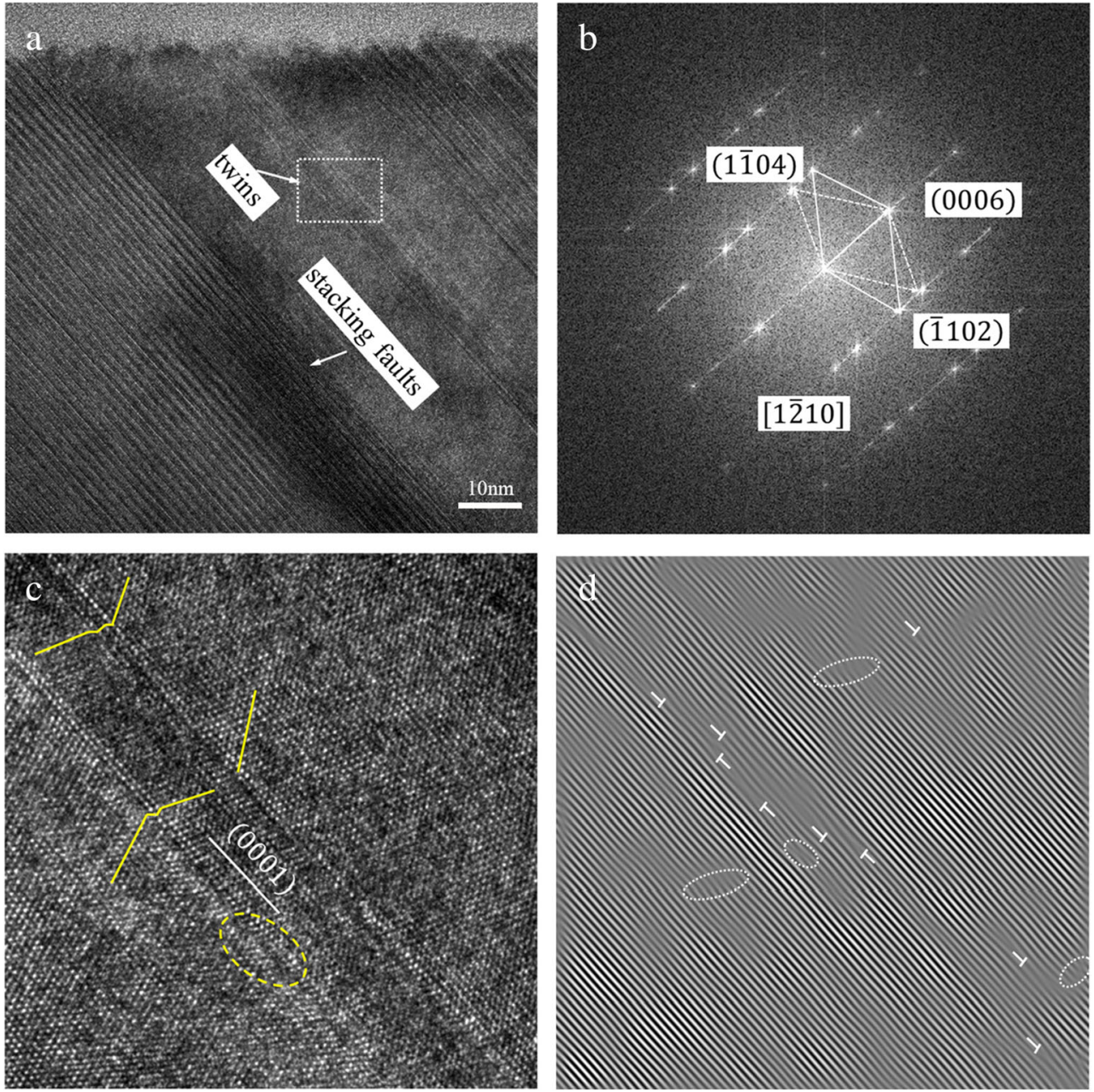

5083/B4C metal matrix [41]. In this case, obviously incoherent atoms scattered along the edge of twins, indicates that dislocations are in existence in the deformation areas. Fig. 10d corresponds to the IFFT pattern by choosing the (0006) and $(000 \overline{6})$ diffraction spots from the FFT pattern. The dislocation structures have high density, which were labeled by ' $\mathrm{T}$ ' to indicate half an atomic plane. In addition, the curly and broken silicon carbide lattice that parallels to the $<0001>$ direction is also highlighted by ellipses. These observed features can unambiguously identify that this twin microstructure is indeed plastic deformation-induced.

\section{Discussions}

\subsection{Formation mechanisms of SFs and twinning}

Through the direct TEM observation, it was found that the subsurface damages under the ductile regime grinding were mainly includes limited dislocations, basal plane
SFs and twins structures. The SFs and twins are mainly concentrated on the easily shearable atomic plane (0001). The basal plane of $6 \mathrm{H}-\mathrm{SiC}$ has maximum inter-planar distance and within the basal plane $<11 \overline{2} 0\rangle$ is the close packed direction with the shortest move distance $(\mathrm{c} / \mathrm{a}=4.907>1.732$ where $\mathrm{c}$ and a are the lattice parameter as $15.117 \AA$ and $3.08065 \AA$, respectively). Thus, this slip system was subjected to less Peierls-Nabarro force than the potential $\{10 \overline{1} 0\}<11 \overline{2} 0>$ prismatic or $\{10 \overline{1} 1\}<1101>$ pyramidal glide system when activate atoms slip. It suggests that the crystal structure factor leads to lower critical resolved shear stresses to slip for the basal plane than those for the prismatic or pyramidal planes. Another possible factor affecting the activation of slip systems is the temperature. High local temperature occurs in the contact zone between the abrasives and work material, especially at such a small cutting depth, which will promote the plastic deformation. Fujita et al. [42] have reported that mono-crystalline $6 \mathrm{H}-\mathrm{SiC}$ undergoing plastic deformation through active $(0001)<11 \overline{2} 0>$ 
glide system at temperatures above $1273 \mathrm{~K}$. Samant et al. [43] also found that critical resolved shear stress for the basal glide system along the $\langle 11 \overline{2} 0\rangle$ direction decreased within 700 to $1300{ }^{\circ} \mathrm{C}$ temperature range.

Therefore, the observed stable SFs could likely be the outcome of the full Burgers vector $1 / 3<11 \overline{2} 0>$ which dissociated into leading dislocation and trailing partial dislocations with vector $1 / 3<1 \overline{1} 00>$ and $1 / 3<10 \overline{1} 0>$, respectively. In the present case, the basal SFs formation mechanism in $6 \mathrm{H}-$ $\mathrm{SiC}$ is equivalent to Shockley partial dislocations $1 / 6<112>$ in cubic 3C-SiC. The slipped atoms in the layer " $\mathrm{B}$ " will detained at the metastable " $\mathrm{C}$ " sites as shown in schematic diagram Fig. 11a. As a result, this motion of partial dislocation by Burgers vector $1 / 3<1 \overline{1} 00>$ in the $6 \mathrm{H}-\mathrm{SiC}$ lattice plane leads to stable SFs formation on the (0001) plane.

What is more, those SFs are also closely related to the formation of basal twinning which might originate from the overlapping of the partial dislocations with SFs on adjacent slip planes. In other words, three collinear $1 / 3$ $<1 \overline{1} 00>$ partials moving on parallel basal planes can make up a full glide of a dissociated $<1 \overline{1} 00\rangle$ prism plane dislocation as shown in Fig. 11b. Besides, there have two potential ways for this twin partials dislocation movement in view of $6 \mathrm{H}-\mathrm{SiC}$ atomic structure, which composed of the sequence stacked $\mathrm{Si}-\mathrm{C}$ bilayers along the $<0001>$ direction. The first way is the glide mode, i.e., shear occurred inside the bilayers and the second way is the shuffle mode, i.e., shear occurred between two bilayers. However, the results of electronic structure calculations with density functional theory suggested that the basal slip on the shuffle set dislocation along the $<1$ $\overline{1} 00>$ direction does not dissociate into partials separated by a stacking fault due to lack of an intermediate energy minimum along this path [44]. Therefore the observed twins in this work should be originated from the glide set along the $<1 \overline{1} 00>$ direction.

\subsection{The mechanism of brittle to ductile transition}

In view of macroscopic removal behavior, the brittle to ductile transition can be understood from a well-known critical penetration depth $d_{c}$ formula established by Bifano et al. in 1991 . Many previous studies have verified that a low enough depth of cut might implement ductile-regime removal for brittle material if the maximum undeformed chip thickness $h_{\max }$ is not exceeding $d_{c}$, which can be specified as [7]:

$d_{c}=0.15\left(\frac{E}{H}\right)\left(\frac{K_{I C}}{H}\right)^{2}$

Based on the parameters given in Table $1, d_{c}$ was calculated to be $36.83 \mathrm{~nm}$. In addition, according to the kinematic relationship between the abrasive and the workpiece in horizontal surface grinding (shown in Fig. 12), the maximum undeformed chip thickness $h_{\max }$ can be expressed as [45]:

$h_{\max }=\left[\frac{4}{C r}\left(\frac{v_{w}}{v_{s}}\right)\left(\frac{a_{p}}{d_{e}}\right)^{1 / 2}\right]^{1 / 2}$

where $C$ is the active grit density, $r$ is the chip-to-thickness ratio, $v_{w}$ is the feed rate, $v_{s}$ is the grinding wheel velocity, $a_{p}$ is the cutting depth, and $d_{e}$ is the equivalent diameter of the grinding wheel. In the present work, the value of $C$ and $r$ are estimated to be equal to 100 and 10 , respectively [46]. The calculated maximum undeformed chip thickness $h_{\max }$ corresponding to varies depth of cut over the range of 0 to $3 \mu \mathrm{m}$ was plotted in Fig. 12. It shows that under the first two sets of depth of cut, the maximum undeformed chip thickness is lower than the critical chip thickness, prompting damage free surface (as shown in Fig. 4c, d).

As $h_{\max }$ increased from 38.57 to $45.87 \mathrm{~nm}$, brittle fracture appeared on the final machined surface (as shown in Fig. 4a, b) and the density of fracture increased. But it can be seen that even though $h_{\max }$ exceed the critical penetration depth, work material was removed in the combined modes of brittle and ductile rather than pure brittle mode. As shown schematically in Fig. 12, cracks exist from the point of critical chip thickness to the top un-machined surfaces along the tool nose. However, some cracks will not penetrate below the machined surface as they are carried away by the following cutting process. Thereby, the mixed characteristics containing brittle and plastic deformation behavior presented on the final machined surface.

Moreover, it is noteworthy that those brittle fractures are distributed at P.B. and G.B. in the form of micro-pits, which are induced by trans-granular crack extending to the free surface in the $\mathrm{SiC}$ grain. This fracture behavior is thought to be the result of tensile stress concentration impinged on the grain boundary due to the SFs and twinning (as simply described in Fig. 13). According to the scratching analytical model developed by Ahn et al. [47], shear stress and compressive stress are distributed in the front and beneath the moving indentation, respectively. The former part is mainly responsible for governing the nucleation and propagations of the SFs and twinning, while under the influence of lateral stress a tensile stress was generated perpendicular to the compressive stress as proposed in Ref. [40].

Then, the induced tension stress initiates and propagates a dilatant crack, leading to the trans-granular fracture which is in agreement with previous SEM observation. As a result some micro pits left on the final ground surface (shown in Fig. 4a, b). Furthermore, high density of the planar defects usually act as preferred crack nucleation sites and propagation paths during the plastic deformation process, since the bonding across the faulting plane is weakened due to the 


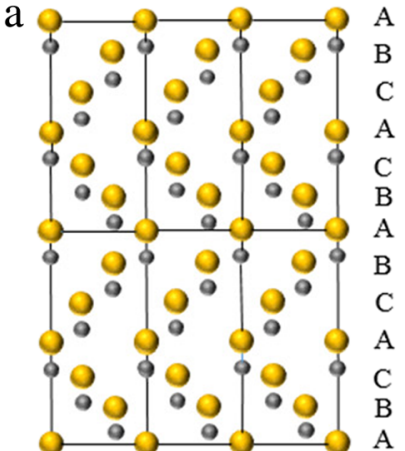

O $\mathrm{Si} \odot \mathrm{C}$

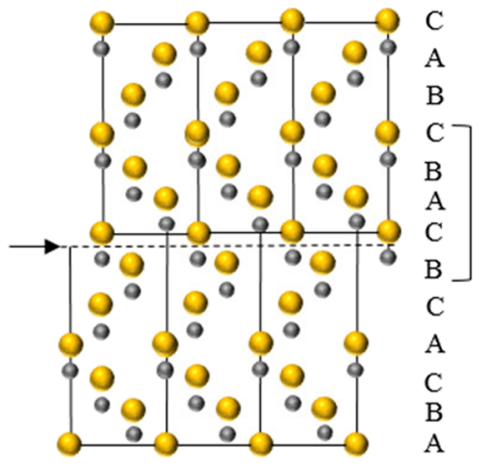

$(1 \overline{2} 10)$

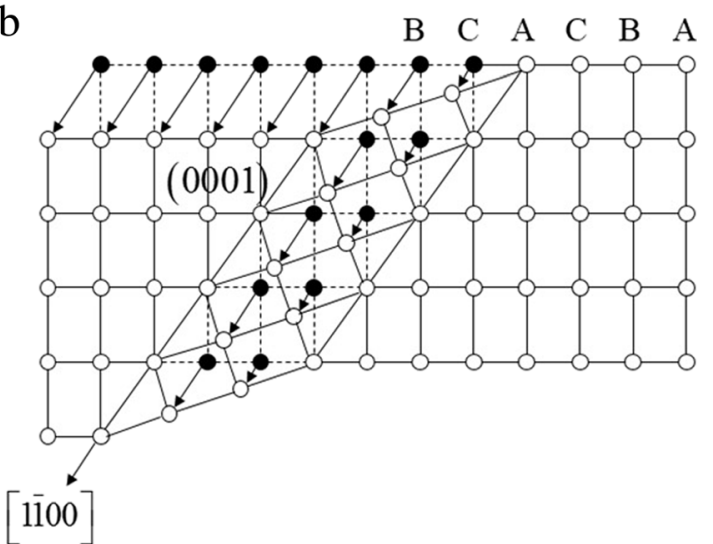

Fig. 11 a the projection of SFs in $6 \mathrm{H}-\mathrm{SiC}$ in $\langle 11 \overline{2} 0>(1-210)$ plane obtained through glide along [11 20$]$. b Geometrically distinguishable basal twins formation process

irregular rearrangement of bonds between the boundary atoms. It might also perhaps the presence of P.B./G.B. and defects make $\mathrm{SiC}$ grains easier to cleavage than single crystal $\mathrm{SiC}$ which enduring a tremendous lattice distortion during grinding process. Therefore, it is reasonably inferred that the cleavage of $\mathrm{RB}-\mathrm{SiC}$ relieving stress prior to the onset of amorphous phase, which is also proved by Raman spectrum and TEM observation.

\section{Conclusions}

This paper investigated the surface and subsurface damages characteristics and formation mechanism of RB-SiC ceramics in ultra-precision grinding. The following results can be summarized based on the above investigations:

1. Damage-free machined surface by ultra-precision grinding of RB-SiC is possible under especially small depth of cut. Below the critical transition depth, machined surface exhibit abundance of plow stripes, pile-up, and free from fracture. Above the critical transition depth, the removal mechanism of RB-SiC ceramic was dominated by both brittle fracture and ductile modes.

2. The major types of residual surface damages in the brittle fracture removal mode were micro-pits, trans-crystalline, and inter-granular micro-cracks. Besides, RB$\mathrm{SiC}$ micro-structures such as impurities, P.B., and G.B. can noticeably influence brittle fracture behavior. The ductile to failure transition mechanisms were discussed: micro crack nucleates at the P.B./G.B. or plastic deformation defects, and consequent propagated within the $\mathrm{SiC}$ grain.

3. Raman spectroscopy and TEM analysis show that there is no amorphous transformation structure in the $\mathrm{SiC}$ and $\mathrm{Si}$ grains, which possible due to the cleavage of $\mathrm{RB}-\mathrm{SiC}$ relieving stress. Additionally, anisotropy stress induced by dislocations in the Si grain causes Si bond component split into different phonon frequencies when depth of cut increased.
Fig. 12 Estimated undeformed maximum chip thickness and the corresponding removal mechanism

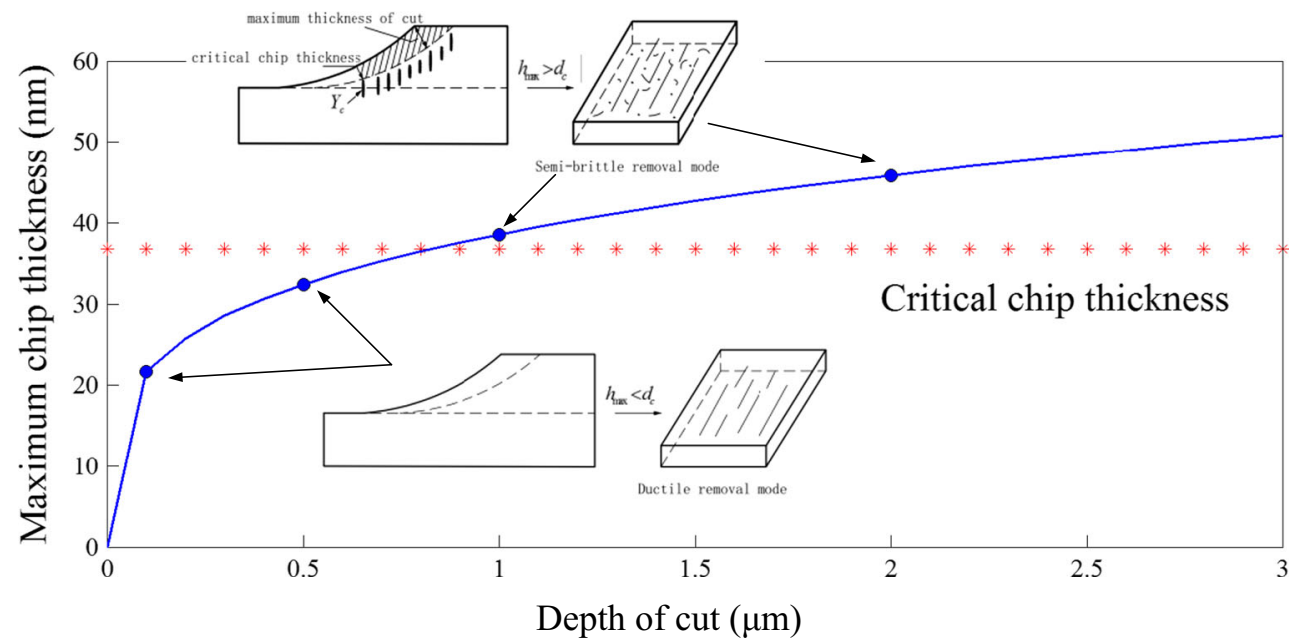




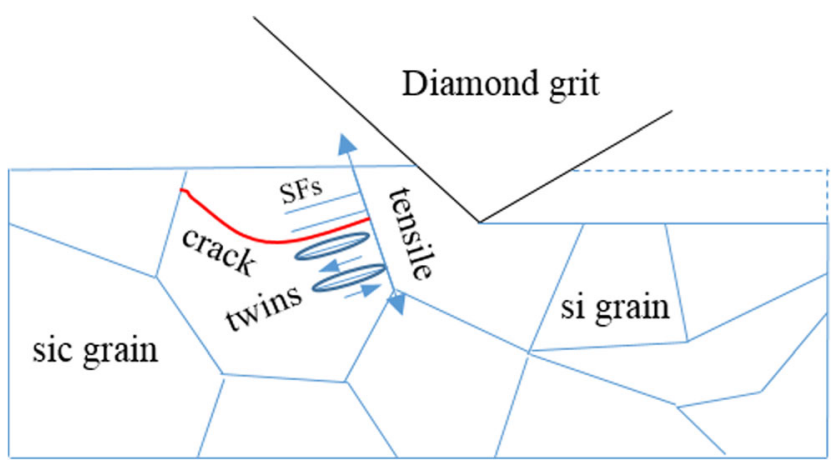

Fig. 13 Schematic diagram of DBT mechanism

4. Dislocations, SFs, and twins are the predominant subsurface damages underneath plastic zone of ultra-precision grinding of $\mathrm{RB}-\mathrm{SiC}$ ceramics. SFs and twins plane are identified (0001), which can be attributed to the basal plane slip on the glide set along the $<1 \overline{1} 00>$ direction.

Acknowledgements This research is financially supported by the Major State Basic Research Development Program of China (973 Program, Grant No. 2011CB013202) and the National Natural Science Foundation of China (Grant No. 51175126).

Open Access This article is distributed under the terms of the Creative Commons Attribution 4.0 International License (http:// creativecommons.org/licenses/by/4.0/), which permits unrestricted use, distribution, and reproduction in any medium, provided you give appropriate credit to the original author(s) and the source, provide a link to the Creative Commons license, and indicate if changes were made.

\section{References}

1. Wijesundara M, Azevedo R (2011) Silicon carbide microsystems for harsh environments. Springer Science \& Business Media

2. Goel S (2014) The current understanding on the diamond machining of silicon carbide. J Phys D Appl Phys 47 (24)

3. Zhong ZW (2003) Ductile or partial ductile mode machining of brittle materials. Int J Adv Manuf Technol 21(8):579-585

4. Yin L, Vancoille EYJ, Lee LC, Huang H, Ramesh K, Liu XD (2004) High-quality grinding of polycrystalline silicon carbide spherical surfaces. Wear 256(1-2):197-207

5. Li B, Ni J, Yang J, Liang S (2014) Study on high-speed grinding mechanisms for quality and process efficiency. Int J Adv Manuf Technol 70(5-8):813-819

6. Li K, Liao TW (1996) Surface/subsurface damage and the fracture strength of ground ceramics. J Mater Process Tech 57(3-4):207220

7. Bifano TG, Dow TA, Scattergood RO (1991) Ductile-regime grinding - a new technology for machining brittle materials. J Eng Ind-T Asme 113(2):184-189

8. Wu H, Roberts SG, Derby B (2001) Residual stress and subsurface damage in machined alumina and alumina/silicon carbide nanocomposite ceramics. Acta Mater 49(3):507-517

9. Huang H, Yin L, Zhou LB (2003) High speed grinding of silicon nitride with resin bond diamond wheels. J Mater Process Tech 141(3):329-336
10. Xu HHK, Jahanmir S, Ives LK (1996) Material removal and damage formation mechanisms in grinding silicon nitride. J Mater Res 11(7):1717-1724

11. Hwang TW, Evans CJ, Malkin S (2000) High speed grinding of silicon nitride with electroplated diamond wheels, part 2: wheel topography and grinding mechanisms. J Manuf Sci E-T Asme 122(1):42-50

12. Xu HHK, Jahanmir S (1994) Simple technique for observing subsurface damage in machining of ceramics. J Am Ceram Soc 77(5): $1388-1390$

13. Denry IL, Holloway JA (2006) Microstructural and crystallographic surface changes after grinding zirconia-based dental ceramics. J Biomed Mater Res B 76B(2):440-448

14. Gu W, Yao Z, Li H (2011) Investigation of grinding modes in horizontal surface grinding of optical glass BK7. J Mater Process Technol 211(10):1629-1636

15. Zhao Q, Liang Y, Stephenson D, Corbett J (2007) Surface and subsurface integrity in diamond grinding of optical glasses on Tetraform 'C'. Int J Mach Tools Manuf 47(14):2091-2097

16. Zhao B, Ding WF, Dai JB, Xi XX, Xu JH (2014) A comparison between conventional speed grinding and super-high speed grinding of $(\mathrm{TiCp}+\mathrm{TiBw}) / \mathrm{Ti}-6 \mathrm{Al}-4 \mathrm{~V}$ composites using vitrified CBN wheel. Int J Adv Manuf Tech 72(1-4):69-75

17. Xi X, Ding W, Li Z, Xu J (2016) High speed grinding of particulate reinforced titanium matrix composites using a monolayer brazed cubic boron nitride wheel. Int J Adv Manuf Tech, 1-10

18. Agarwal S, Rao PV (2008) Experimental investigation of surface/ subsurface damage formation and material removal mechanisms in SiC grinding. Int J Mach Tools Manuf 48(6):698-710

19. Zhang B, Zheng X, Tokura H, Yoshikawa M (2003) Grinding induced damage in ceramics. J Mater Process Technol 132(1-3):353364

20. Zhang Q, To S, Zhao Q, Guo B (2015) Amorphization and C segregation based surface generation of reaction-bonded $\mathrm{SiC} / \mathrm{Si}$ composites under micro-grinding. Int J Mach Tools Manuf 95: $78-81$

21. Xu HHK, Padture NP, Jahanmir S (1995) Effect of microstructure on material-removal mechanisms and damage tolerance in abrasive machining of silicon-carbide. J Am Ceram Soc 78(9):2443-2448

22. Gao J, Chen J, Liu G, Yan Y, Liu X, Huang Z (2010) Role of microstructure on surface and subsurface damage of sintered silicon carbide during grinding and polishing. Wear 270(1-2):88-94

23. Venkatachalam S 2007 Predictive modeling for ductile machining of brittle materials. Disseratation, Georgia Institute of Technology

24. Gopal AV, Rao PV (2004) A new chip-thickness model for performance assessment of silicon carbide grinding. Int J Adv Manuf Technol 24(11-12):816-820

25. Wang C, Chen J, Fang Q, Liu F, Liu Y (2016) Study on brittle material removal in the grinding process utilizing theoretical analysis and numerical simulation. Int J Adv Manuf Technol 87(9): 2603-2614

26. Mishra M, Tangpatjaroen C, Szlufarska I (2014) Plasticitycontrolled friction and wear in nanocrystalline SiC. J Am Ceram Soc 97(4):1194-1201

27. Goel S, Stukowski A, Luo X, Agrawal A, Reuben RL (2013) Anisotropy of single-crystal $3 \mathrm{C}-\mathrm{SiC}$ during nanometric cutting. Model Simul Mater Sc 21 (6)

28. Xiao GB, To S, Zhang GQ (2015) The mechanism of ductile deformation in ductile regime machining of $6 \mathrm{H} \mathrm{SiC}$. Comput Mater Sci 98:178-188

29. Harima H (2006) Raman scattering characterization on SiC. Microelectron Eng 83(1):126-129

30. Lin SH, Chen ZM, Li LB, Ba YT, Liu SJ, Yang MC (2012) Investigation of micropipes in $6 \mathrm{H}-\mathrm{SiC}$ by Raman scattering. Physica B 407(4):670-673 
31. Nakashima S, Harima H (1997) Raman investigation of SiC polytypes. Phys Status Solidi A 162(1):39-64

32. Iqbal Z, Veprek S (1982) Raman-scattering from hydrogenated microcrystalline and amorphous-silicon. J Phys C Solid State 15(2): 377-392

33. Yan J, Asami T, Kuriyagawa T (2008) Nondestructive measurement of machining-induced amorphous layers in single-crystal silicon by laser micro-Raman spectroscopy. Precis Eng 32(3):186195

34. Yan JW, Asami T, Harada H, Kuriyagawa T (2009) Fundamental investigation of subsurface damage in single crystalline silicon caused by diamond machining. Precis Eng 33(4):378-386

35. Groth B, Haber R, Mann A (2015) Raman micro-spectroscopy of polytype and structural changes in $6 \mathrm{H}$-silicon carbide due to machining. Int J Appl Ceram Tec 12(4):795-804

36. Ness JN, Page TF (1986) Microstructural evolution in reactionbonded silicon-carbide. J Mater Sci 21(4):1377-1397

37. Ni ZH, Fan HM, Feng YP, Shen ZX, Yang BJ, Wu YH (2006) Raman spectroscopic investigation of carbon nanowalls. J Chem Phys 124 (20)

38. Song SG, Vaidya RU, Zurek AK, Gray GT (1996) Stacking faults in $\mathrm{SiC}$ particles and their effect on the fracture behavior of a $15 \mathrm{Vol}$ Pct SiC/6061-Al matrix composite. Metall Mater Trans A 27(2): 459-465

39. Hong MH, Samant AV, Pirouz P (2000) Stacking fault energy of 6H-SiC and 4H-SiC single crystals. Philos Mag A 80(4):919-935
40. Shih CJ, Meyers MA, Nesterenko VF, Chen SJ (2000) Damage evolution in dynamic deformation of silicon carbide. Acta Mater 48(9):2399-2420

41. Li Y, Zhao YH, Liu W, Zhang ZH, Vogt RG, Lavernia EJ, Schoenung JM (2010) Deformation twinning in boron carbide particles within nanostructured Al 5083/B4C metal matrix composites. Philos Mag 90(6):783-792

42. Fujita S, Maeda K, Hyodo S (1987) Dislocation glide motion in $6 \mathrm{~h}$ sic single-crystals subjected to high-temperature deformation. Philos Mag A 55(2):203-215

43. Samant AV, Zhou WL, Pirouz P (1998) Effect of test temperature and strain rate on the yield stress of monocrystalline $6 \mathrm{H}-\mathrm{SiC}$. Phys Status Solidi A 166(1):155-169

44. Kiani S, Leung KWK, Radmilovic V, Minor AM, Yang JM, Warner DH, Kodambaka S (2014) Dislocation glide-controlled room-temperature plasticity in $6 \mathrm{H}-\mathrm{SiC}$ single crystals. Acta Mater 80:400 406

45. Malkin S (1989) Grinding technology, theory and applications of machining with abrasives. Ellis Horwood Limited, Chichester

46. Mayer JE Jr, Fang GP, Kegg RL (1994) Effect of grit depth of cut on strength of ground ceramics. Ann CIRP 43:309-312

47. Ahn Y, Farris TN, Chandrasekar S (1998) Sliding microindentation fracture of brittle materials: role of elastic stress fields. Mech Mater 29(3-4):143-152 